\title{
A Comparative Analysis of Ophthalmology Resident Physician Performance Based on Use of Parental Leave
}

\author{
Michael J. Fliotsos, BS ${ }^{1}$ Sidra Zafar, MBBS ${ }^{1}$ Fasika A. Woreta, MD, MPH ${ }^{1}$ Peter M. Ugoh, BSA ${ }^{2}$ \\ Divya Srikumaran, $\mathrm{MD}^{1}$ \\ ${ }^{1}$ Wilmer Eye Institute, Department of Ophthalmology, Johns Hopkins \\ University School of Medicine, Baltimore, MD \\ ${ }^{2}$ School of Medicine, Baylor College of Medicine, Houston, TX \\ Address for correspondence Divya Srikumaran, MD, Wilmer Eye \\ Institute, Odenton, 1106 Annapolis Rd., Odenton, MD 21113 \\ (e-mail: dsrikum1@jhmi.edu).
}

Journal of Academic Ophthalmology 2021;13:e1-e4.

\begin{abstract}
Background Taking parental leave during ophthalmology residency may be perceived to negatively affect resident surgical volume and educational outcomes. However, limited data exist on whether taking parental leave is associated with objective measures of resident performance. The objective of the present study was to determine the association between taking parental leave and key measures of resident performance.

Methods Educational records of ophthalmology resident physicians who graduated from 2015 to 2019 at the Johns Hopkins University School of Medicine Wilmer Eye Institute were reviewed. Measures of resident performance assessed were Ophthalmic Knowledge Assessment Program scores, number of publications during residency, Accreditation Council for Graduate Medical Education milestones scores, and surgical volumes. These outcomes were compared for residents who took parental leave compared with their peers who did not take parental leave.

Keywords

- parental leave

- resident education

- ACGME milestones

- surgical volume

- ophthalmology

- ophthalmology residency

Results Twenty-five residents were included in the study. Four female residents (16\%) took parental leave 8 weeks in duration. There were no significant differences between residents who did and did not take parental leave when considering mean Ophthalmic Knowledge Assessment Program scores $(p=0.27)$, number of publications during residency $(p=0.19)$, milestone scores ( $p$-value range $0.09-0.40)$, and surgical volume by subspecialty category ( $p$-value range $0.11-0.45$ ).

Conclusion Parental leave did not negatively influence any of the studied measures of resident performance.
\end{abstract}

Parental leave policies in graduate medical education (GME) programs in the United States garner active discussion between residents, program directors (PD's), and national policymakers. Parental leave policies for residents are typically less common and less well-established than those for attending faculty. ${ }^{1}$ Even when a program has a specific policy in place, there can often be variability in implementation ${ }^{2}$; for some, a resident's parental leave is a combination of vacation, sick, travel, and other miscellaneous days, ${ }^{3}$ contributing to inconsistencies between departments and institutions. received

August 18, 2020

accepted after revision

October 12, 2020
DOI https://doi.org/

10.1055/s-0040-1721465. ISSN 2475-4757.

\footnotetext{
(C) 2021. The Author(s).

This is an open access article published by Thieme under the terms of the Creative Commons Attribution-NonDerivative-NonCommercial-License, permitting copying and reproduction so long as the original work is given appropriate credit. Contents may not be used for commercial purposes, or adapted, remixed, transformed or built upon. (https://creativecommons.org/ licenses/by-nc-nd/4.0/)

Thieme Medical Publishers, Inc., 333 Seventh Avenue, 18th Floor, New York, NY 10001, USA
} 
Importantly, residents have reported perceived stigma and bias regarding childbearing and use of leave policies. ${ }^{4}$ A recent survey of orthopaedic surgery ${ }^{5}$ and general surgery ${ }^{6}$ PD's found that the majority believed that parenthood negatively affected female residents' scholarly activities and clinical abilities, respectively. The decision to take parental leave during residency has been identified as a source of decreased career satisfaction for female residents. ${ }^{7}$ Institutional support of parental leave policies is increasingly seen by many residents as an important aspect of enhancing wellness. $^{8}$

While a prior investigation in general surgery ${ }^{9}$ found no significant differences in surgical experience between residents who did and did not experience pregnancy during training, there is a lack of information regarding the impact of parental leave policies on resident educational outcomes in ophthalmology residency. In a prior survey of 82 academic, community, and military programs, ophthalmology PDs generally perceived that having a child during residency had a negative effect on scholarly activities and surgical skills/ volume. ${ }^{10}$ It remains unknown whether this perception is accurate in terms of measurable data regarding resident performance. The aim of the present study was to determine the impact of ophthalmology resident parental leave on Ophthalmic Knowledge Assessment Program (OKAP) scores, Accreditation Council for Graduate Medical Education (ACGME) milestone assessments, and surgical volumes when accounting for demographic and educational factors.

\section{Methods}

We conducted a retrospective review of educational records of the 2015 to 2019 graduating residency classes at the Wilmer Eye Institute at the Johns Hopkins University School of Medicine (JHUSOM). Residency application information, educational outcomes data, demographic information, and length of parental leave taken (if applicable) were extracted from records maintained by our program. Parental leave is defined by institution-wide policy as a "new child accommodation," which is distinct from time off to care for a sick child who is not a newborn; this leave can be taken by either parent, regardless of gender, and is provided to all residents expecting a "biological or adopted child, or stepchild." ${ }^{11}$ In our study, the residents took 8 weeks of childbearing postpartum parental leave, specifically. The policy of our department was based on the standard minimum 8 weeks allocated by our institution's GME office, while also adhering to guidelines from the American Board of Ophthalmology (ABO). During the study period, the policy of the $A B O$ was that residents must complete at least 6 months of training per year of residency. ${ }^{12}$ The parental leave time permitted for residents in our department is separate from vacation, sick leave, or Family and Medical Leave Act allocations. Resident performance was assessed by annual OKAP scores, number of publications during residency, average ACGME milestones scores for each of the six core competencies, and surgical volumes by surgical subspecialty category. Resident data were de-identified for statistical analysis.
Mann-Whitney U tests were used to compare the above continuous outcome variables between residents who did and did not take parental leave. All statistical work was accomplished using Stata version 13.0 (StataCorp, College Station, TX), with statistical significance defined as $p<0.05$. Our study was approved by the JHUSOM Institutional Review Board.

\section{Results}

Twenty-five residents were included in the study. Four female residents (16\%) took parental leave 8 weeks in duration; none were required to extend their training. There were no significant differences between residents who took leave versus those who did not when considering mean OKAP scores (67.5 for parental leave group vs. 63.0 for nonparental leave group, $p=0.27$ ), number of publications during residency ( 4.8 vs. 3.7, $p=0.19$ ), ACGME milestone scores (2.8-3.7 vs. 3.3-3.9, $p$-value range $0.09-0.40$ ), and surgical volume by subspecialty (16-235 vs. 13.4-245, p-value range 0.11-0.45; - Table 1 ). Our multivariate linear regression model found no significant differences in measures of performance between residents who took parental leave versus those who did not when adjusting for the factors outlined above. All of the residents who pursued fellowship training during the time period study matched into the specialty fellowship of their choice.

\section{Discussion}

Our investigation demonstrated no significant differences across multiple educational performance metrics between residents who took parental leave and those who did not in our ophthalmology residency program. Our study results reinforce and expand on data reported in a previous study, where there was no difference in cataract surgery volume for female residents taking leave. ${ }^{13}$ Surgical volume was insignificantly lower for our residents taking parental leave across all surgical subcategories, including cataract, retina, glaucoma, and oculoplastic surgery. There was no significant difference regarding performance on the OKAP, a series of annual examinations which are correlated with passage of the ABO Written Qualifying Examination. ${ }^{14}$ Our results demonstrated no significant differences based on either sex or parental leave status regarding ACGME milestone assessments. While prior studies in other fields have demonstrated a gender gap regarding resident milestone evaluation, ${ }^{15}$ differences in resident evaluation based on use of parental leave had not been previously investigated in an ophthalmology residency program.

Among trainees taking parental leave, the desire not to lengthen training is a main determinant of length of leave taken. ${ }^{16}$ The previous policy of the ABO stated that "duration of training is a specific requirement for board eligibility. If [a resident has] taken time off or extended leave ... [they] will need to make up the missed time in consultation with [the] Residency Program Chair or Director. The ABO does not accept less than one postgraduate year-1 (PGY-1) internship year, followed by 36 months of ACGME-accredited residency training in ophthalmology." 12 This policy posed a challenge 
Table 1 Comparison of performance metrics between residents who did and did not take parental leave

\begin{tabular}{|c|c|c|c|}
\hline & $\begin{array}{l}\text { Parental leave } \\
(n=4) \\
\text { Mean (SD) }\end{array}$ & $\begin{array}{l}\text { No parental leave } \\
(n=21) \\
\text { Mean (SD) }\end{array}$ & p-Value \\
\hline \multicolumn{4}{|l|}{ Academic } \\
\hline OKAP scores & $67.5(15.1)$ & $63.0(22.8)$ & 0.27 \\
\hline \multicolumn{4}{|l|}{ Scholarly activities } \\
\hline Number of publications during residency & $4.8(2.5)$ & $3.7(2.8)$ & 0.19 \\
\hline \multicolumn{4}{|c|}{ Accreditation Council for Graduate Medical Education (ACGME) milestones } \\
\hline Patient care (PC) & $3.4(0.6)$ & $3.8(0.3)$ & 0.31 \\
\hline Medical knowledge (MK) & $3.7(0.6)$ & $3.9(0.6)$ & 0.40 \\
\hline Systems-based practice (SBP) & $3.1(0.7)$ & $3.3(0.5)$ & 0.26 \\
\hline Practice-based learning and improvement (PBLI) & $3.5(1.0)$ & $3.6(0.5)$ & 0.17 \\
\hline Professionalism (PROF) & $2.8(0.5)$ & $3.3(0.6)$ & 0.09 \\
\hline Interpersonal and communication skills (ICS) & $3.3(0.3)$ & $3.6(0.5)$ & 0.37 \\
\hline \multicolumn{4}{|l|}{ Surgical volume } \\
\hline Cataract surgery & $235(73.5)$ & $245(74.5)$ & 0.45 \\
\hline $\begin{array}{l}\text { Laser eye surgery (YAG capsulotomy, } \\
\text { trabeculoplasty, iridotomy, and } \\
\text { pan-retinal photocoagulation) }\end{array}$ & $56.8(15.4)$ & $55.1(20.8)$ & 0.41 \\
\hline Keratoplasty & $16.0(10.2)$ & $13.40(6.0)$ & 0.42 \\
\hline Pterygium, conjunctival, and other corneal surgery & $28.3(15.4)$ & $21.9(7.5)$ & 0.23 \\
\hline Keratorefractive surgery & $19.0(11.0)$ & $15.7(9.72)$ & 0.21 \\
\hline Strabismus & $71.5(45.4)$ & $43.0(22.1)$ & 0.08 \\
\hline Glaucoma surgery & $32.5(9.7)$ & $36.2(17.3)$ & 0.42 \\
\hline Retina vitreous & $18.3(9.0)$ & $25.4(14.5)$ & 0.23 \\
\hline Intravitreal injections & $75.0(41.9)$ & $71.2(24.1)$ & 0.42 \\
\hline Oculoplastic surgery & $159.8(32.5)$ & $132.50(32.7)$ & 0.11 \\
\hline Globe trauma & $21.5(8.3)$ & $16.6(4.3)$ & 0.11 \\
\hline
\end{tabular}

Abbreviation: OKAP, Ophthalmic Knowledge Assessment Program.

for some programs, as they attempted to balance the length of parental leave allowed for their residents while also completing a 36 month time-based training requirement.

However, the $A B O$ recently changed its policy to support board eligibility based on ACGME milestone-based training requirements, ${ }^{17}$ requiring a minimum 6 months of training be completed per year of residency. This decision will likely alleviate some undue stress to residents contemplating parenthood in a competency-based training requirement system, as they would not be categorically required to extend the length of their training. Outside of ophthalmology, the most recent review of evidence found that only one-third of American Board of Medical Specialty member organizations had policies that allow PD's to seek exemption from time-based training requirements for residents taking leave. ${ }^{15}$ Our study results demonstrate that among the residents at our institution who took parental leave, measurable indicators of resident performance were comparable to those who did not, while still graduating on time. This is a finding that will provide valuable information to
PDs in determining appropriate policies for parental leave in the future.

Resident wellness is a priority for our institution's GME office, which offers many initiatives to address resident physical, mental, and financial wellness. For example, there are dedicated individuals in each Department to help residents in scheduling important appointments during business hours, a University Mental Health services staff that is available for inperson and remote counseling, and an emergency financial aid fund for extenuating circumstances. There is a GME-wide policy of providing a minimum of 8 weeks paid parental leave, consistent with grant funding policies for parental leave. ${ }^{11}$ In addition, residents can take advantage of university-wide childcare benefits, including an on-campus childcare center and limited number of days of paid back-up childcare options, as well as dependent care flexible spending accounts to help improve affordability of childcare. In our department specifically, there is a Mother's room where employees can pump breastmilk in privacy, both within the hospital as well as in the ophthalmic surgery center. Our residency program is also mid- 
size (five residents per year), and our department hired a physician's assistant to help with miscellaneous clinical responsibilities; both of these factors made redistribution of work due to parental leave more feasible.

In instances where a resident in our program was contemplating having a child in advance, we made every effort to coordinate schedules such that they would miss a rotation that would be less disruptive for their education. Furthermore, surgical experience with cataract surgery is distributed among multiple rotations in our program which help to reduce the impact of missing a single rotation for leave. In addition, there is a consult rotation in the PGY-3 year and an elective block in the PGY-4 year that provide some flexibility which can be used to supplement the resident's clinical experiences in a particular subspecialty area that was missed.

Limitations of our study include that it is single center analysis and thus might not be generalizable to other programs and specialties. Our residency program has ranked in the top ten ophthalmology programs based on a recent national survey, ${ }^{18}$ which provides an additional potential source of bias regarding the academic abilities of the study cohort. In addition, the small cohort of residents limits our statistical power. Future studies should focus on differences among multiple institutions to account for variations of parental leave policies, as well as accounting for the effect of duration of parental leave on metrics of ophthalmology resident education. Our findings add to the presently available literature, in that they demonstrate that ophthalmology trainees who took parental leave performed at comparable levels as their peers who did not take leave in our program.

\section{Conclusion}

Parental leave did not negatively influence any of our studied measures of resident performance. Our results support that idea that residents may be able to take parental leave and graduate on time provided that they meet competencybased requirements. Future research should focus on the effect of parental leave among multiple institutions, as well as determining if length of leave has a proportional impact on resident educational attainment.

\section{Disclosures}

D.S. is a consultant for Alcon and receives NIH grant support.

\section{Funding}

This research did not receive any specific grant from funding agencies in the public, commercial, or not-forprofit sectors.

\section{References}

1 Magudia K, Bick A, Cohen J, et al. Childbearing and family leave policies for resident physicians at top training institutions. JAMA 2018;320(22):2372-2374

2 Sandler BJ, Tackett JJ, Longo WE, Yoo PS. Pregnancy and parenthood among surgery residents: results of the first nationwide survey of general surgery residency program directors. J Am Coll Surg 2016;222(06):1090-1096

3 Kuehn BM. Fixing the parent trap for resident physicians. JAMA 2020;323(12):1119-1121

4 Altieri MS, Salles A, Bevilacqua LA, et al. Perceptions of surgery residents about parental leave during training. JAMA Surg 2019; 154(10):952-958

5 Nemeth C, Roll E, Mulcahey MK. Program directors' perception of pregnancy and parenthood in orthopedic surgery residency. Orthopedics 2020;43(02):e109-e113

6 Sandler BJ, Tackett JJ, Longo WE, Yoo PS. Pregnancy and parenthood among surgery residents: Results of the first nationwide survey of general surgery residency program directors. J Am Coll Surg 2016;222(06):1090-1096

7 Rangel EL, Lyu H, Haider AH, Castillo-Angeles M, Doherty GM, Smink DS. Factors associated with residency and career dissatisfaction in childbearing surgical residents. JAMA Surg 2018;153 (11):1004-1011

8 Magudia K, Ng TSC, Bick AG, et al. Parenting while in training: a comprehensive needs assessment of residents and fellows. J Grad Med Educ 2020;12(02):162-167

9 Onesti JK, Elliott DR, Chung MH, Schlatter MG, Van Spronsen CR, Koehler TJ. Can pregnant surgery residents make the cut? J Am Coll Surg 2013;217:S124. Doi: 10.1016/j.jamcollsurg.2013.07.285

10 Wang KM, Lee B, Woreta FA, et al. Parental leave policy for ophthalmology residents: results of a nationwide cross-sectional study of program directors. J Surg Educ 2020:1-10 (e-pub ahead of print). Doi: 10.1016/j.jsurg.2020.08.034

11 Johns Hopkins University New Child Accommodations for FullTime Graduate Students and Postdoctoral Trainees. Accessed September 18, 2020 at: https://www.jhu.edu/assets/uploads/ 2017/06/newchildaccommgradandpostdoc.pdf

12 Varda BK, Glover M IV. Specialty board leave policies for resident physicians requesting parental leave.JAMA 2018;320(22):2374-2377

13 Gong D, Winn BJ, Beal CJ, et al. Gender differences in case volume among ophthalmology residents. JAMA Ophthalmol 2019;137 (09):1015-1020

14 Lee AG, Oetting TA, Blomquist PH, et al. A multicenter analysis of the ophthalmic knowledge assessment program and American Board of Ophthalmology written qualifying examination performance. Ophthalmology 2012;119(10):1949-1953

15 Dayal A, O'Connor DM, Qadri U, Arora VM. Comparison of male vs female resident milestone evaluations by faculty during emergency medicine residency training. JAMA Intern Med 2017;177 (05):651-657

16 Stack SW, Jagsi R, Biermann JS, et al. Maternity leave in residency: a multicenter study of determinants and wellness outcomes. Acad Med 2019;94(11):1738-1745

17 Requirements for Certification American Board of Ophthalmology. Accessed May 1, 2020 at: https://abop.org/become-certified/ requirements/

18 Ophthalmology Times Bascom Palmer tops in annual program survey. 4 October 2019. Accessed September 18, 2020 at: https:// www.ophthalmologytimes.com/view/bascom-palmer-tops-annual-program-survey 